\title{
Direito do Consumidor: Exigência do Capitalismo ou Transformação Social?
}

\section{eAndressa Caldas}

Artigo elaborado a partir de monografia apresentada à disciplina de Direito Civil Contemporâneo, lecionada pela Prof $^{\mathrm{a}} \mathrm{Dr}^{\mathrm{a}}$ CARMEM LUCIA SILVEIRA RAMOS, no Programa de Pós-Graduação em Direito, da Universidade Federal do Paraná.

\section{Sociedade de consumo e limitação da autonomia privada}

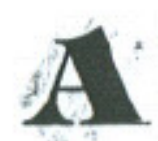

s múltiplas transformações ocorridas nas sociedades ocidentais contemporâneas - que utilizam o contrato como instrumento por excelência para promover a circulação da riqueza - exigiram mudanças em vários aspectos da teoria contratual. Destaca-se, dentre tais mudanças, uma maior limitação do campo da autonomia privada!

Já na década de 70, descrevendo com precisão a tão propalada sociedade de consumo, ERICH FROMM afirma que "a ambi- çāo humana, tendo por freguês o mundo inteiro, torna-se ilimitada, e o homem se enche de desgosto com a futilidade da busca interminável". Prossegue o autor afirmando que "a sociedade se torna um pó desorganizado de indivíduos" e "as comunidades industrializadas negligenciam os próprios objetivos pelos guais se torna justificável a aquisição de riqueza, em sua preocupaçăo com os meios pelos quais essa riqueza pode ser adquirida"2. CLÁUDIA LIMA MARQUES demonstra que, na sociedade de consumo, há uma despersonalizaçāo do comércio jurídico, através de seu sistema de produção e de

1. No entender da prolessora Ana Prata, "a noçăo de autonomia privada năo é atemporal, nem imutável. Ela ganha autonomia e relevo conceitual ligada à concepçăo jurídica do liberalismo econômico, como pressuposto da noçăo de negócio jurídico e vai sofrendo uma desvalorizaçăo que acompanha o transformar deste último conceito". Assevera ainda que: "essa desvalorizaçäo só existe se tomada a sua noção clássica como noçăo imutável; na realidade, como se verá, a transformaçăo do conceito de negócio tem de ser acompanhada por uma transformaçăo da própria noçăo de autonomia privada".PRATA, Ana. A tutela constitucional da autonomia privada. Coimbra: Almedina, 1982, p. 25.

2. FROMM, Erich. Psicanálise da sociedade contemporânea. Rio de Janeiro: Zahar, 1974, p. 214. 
distribuição em grande quantidade, fato que ensejou a utilização dos métodos de contratação de massa ${ }^{3}$.

Nesta conjuntura mencionada, o contrato passa a ter um maior impacto nas sociedades ocidentais, ultrapassando a relação intersubjetiva para atingir grandes coletividades, sendo por alguns autores considerado como uma verdadeira "operação econômica distributiva" ${ }^{\text {" }}$.

A necessidade de resolver situações jurídicas subjetivas patrimoniais ${ }^{5}$ decorrentes de contratos em que há desigualdade material das partes passou a exigir uma nova forma de intervenção do Estado na reformulação do conteúdo dos contratos de consumo, juntamente com a possibilidade interventiva a posteriori do Poder Judiciário.

\section{As transformações trazidas pelo Código de Defesa do Consumidor}

No Brasil, em observância ao disposto no texto constitucional - mais especificamente aos arts. $5^{2}, \mathrm{XXXII} ; 24, \mathrm{~V} ; 170, \mathrm{~V}$, e art. 48, do Ato das Disposições Constitucionais Transitórias - a Lei no 8.078, de 11 de setembro de 1990 (Código de Defesa do Consumidor) aprofundou tais modificações, fazendo com que vários institutos de prote. ção ao consumidor conduzissem a transformações efetivas do conteúdo da autonomia privada.

A Constituição Federal de 1988, com a sua necessária incidência direta nas relaçōes privadas (antes somente reguladas pelo Código Civil), alterou significativamente a noção de autonomia privada.

Algumas evoluçōes doutrinárias já verificadas na metade do século, retornam com maior força, para serem aplicadas nos contratos de consumo. Das quais, destacam-se:

a) a possibilidade de revisão de contratos em curso, suas causas contemporâneas e supervenientes, utilizando-se a teoria clássica da imprevisão e da teoria alemã da quebra da base do negócio;

b) a possibilidade de controle do Poder Judiciário sobre o conteúdo dos contratos (cujo rígido estabelecimento, segundo a teoria clássica, dar-se-ia "livremente" pelas partes), admitindo-se a modificação de cláusulas contratuais que demonstrem excessiva onerosidade;

c) o controle legislativo prévio, a proteção judicial contra as cláusulas abusivas, e o controle, administrativo e judicial, das cláusulas gerais dos contratos.

3. MARQUES, Cláudia Lima. Contratos no Código de Defesa do Consumidor: o novo regime das relạ̄oes contratuais. 3.ed. rev. ampl. São Paulo: Revista dos Tribunais, 1998, p. 49.

4. LORENZETTI, ob. cit., p. 541.

5. Para PERLINGIERI, "a eficácia do fato com referência a um centro de interesses, que encontra a sua imputação em um sujeito destinatário, traduz-se em situaçŏes subjetivas juridicamente relevantes". Segundo o autor, as situaçōes jurídicas subjetivas devem ser compreendidas sob vários aspectos (quanto aos efeitos, quanto ao perfil do interesse, quanto ao perfil dinâmico, quanto ao exercício, quanto ao perfil funcional e quanto ao perfil normativo). PERLINGIERI, Pietro. Perfis do direito civil. Introdução ao direito civil constitucional. Rio de Janeiro: Renovar, 1997, pp.105-107. 
Além disso, no âmbito processual, o Código de Defesa do Consumidor rege as ações individuais e as ações coletivas. No âmbito das ações individuais, verifica-se a possibilidade de determinação de competência pelo domicílio do autor (art. 101, I, $\mathrm{CDC}$ ), a vedação da denunciação da lide, em alguns casos (art. 88, CDC), a possibilidade de inversão do ônus da prova em favor do consumidor (art. 6, VIII, CDC), entre cutras regras que complementam a tutela do consumidor. No que tange às açōes coletivas, destaca-se o novo tratamento à coisa julgada e à ação coletiva ressarcitória dos danos pessoalmente sofridos pelos consumidores ${ }^{6}$.

Instala-se, portanto, com maior ou menor intensidade, no âmbito das relações contratuais de consumo, uma nova pauta de princípios que apontam para: (I) a relativizaçăo do princípio da intangibilidade do conteúdo do contrato; (II) a revitalização da boa-fé como princípio basilar das relações de consumo; (III) a proteção contra cláusulas abusivas; (IV) o controle das cláusulas gerais dos contratos; $(\mathrm{V})$ a modificação das cláusulas contratuais em virtude de excessiva onerosidade; (VI) e a ampliação da responsabilidade civil contratual, ao lado da aceitação da aplicabilidade da responsabilidade civil objetiva.

\section{Direito do consumidor: uma exigência do capitalismo}

Ainda que a redução do campo da autonomia privada configure uma tendên- cia que já vinha se desenvolvendo muito antes do advento do movimento consumerista, são inegáveis as transformaçōes trazidas pelo Código de Defesa do Consumidor brasileiro face à teoria contratual.

Contudo, o que também não se pode negar, é que tais mudanças - ainda que imbuídas de um espírito mais socializante e ético - respondem a uma exigência, mais uma vez de sobrevivência, do sistema capitalista, atualmente de roupagem globalizante e neoliberal.

Assim, não se pode olvidar que, embora mais restrito, o princípio da autonomia privada permanece sendo o instrumento pragmático a serviço da circulação de mercadorias e da acumulação do capital.

CARLOS FERREIRA DE ALMEIDA demonstra ser simplificada e exagerada a afirmação de que as normas do direito privado patrimonial se orientam sempre contra os interesses dos consumidores ou à margem deles. Pondera o referido autor que o problema é mais complexo, pois "a história moderna da legislação civil e comercial é, em parte, uma seqüência de quadros em que as normas imperativas representam, em graus diversos, os interesses de certas classes ou grupos, em desfavor de outros, e assumem os valores que em cada época ou lugar se consideram como fundamentais na estrutura social" $"$.

Assim é que, no entendimento de alguns juristas e analistas econômicos, "a

6. GRINOVER, Ada Pellegrini, et al. Código brasileiro de defesa do consumidor: comentado pelos autores do anteprojeto. Rio de Janeiro: Forense Universitária, 1998, pp. 608-609.

7. ALMEIDA, Carlos Ferreira de. Os direitos dos consumidores. Coimbra: Almedina, 1982, p. 24. 
partir da implantação do modelo político neoliberal, e no intuito de reverter o quadro das crises capitalistas decorrentes da queda do poder aquisitivo levada ao extremo no desemprego e, portanto, na impossibilidade de consumir das grandes massas da sociedade, voltaram-se as atenções para o consumidor $^{n 8}$.

Demonstra ALMEIDA que há uma repercussão favorável aos consumidores nos preceitos que impõem "um certo conteúdo ético mínimo no desenvolvimento da actividade de relevância jurídica das empresas", citando como exemplo as normas so. bre concorrência desleal. "Mas não haja ilusões" - ressalta o autor, pois - "o sentido directo da exigibilidade do comportamento honesto é determinado pela protecção do conjunto dos produtores, no estabelecimento das regras do jogo entre si, e na garantia de que o sistema se não corrompe ao ponto de não merecer o crédito social bastante para a manutenção dos privilégios sociais"

Agregue-se a isso a perspectiva do quue sé temin máa recentementc denominado de análise econômica do direito, cujo pai, RICHARD POSNER (autor de Economic Analysis of Law), considera subjetivo e individual o conceito de justiça, sugerindo sua substituição pela noção de eficiência ${ }^{10}$.
Nesta perspectiva traçada e a par das tendências mais recentes das escolas econômicas, pode-se dizer - da mesma forma que faz EROS GRAU a respeito do Estado do bem-estar - que também o direito do consumidor (e com muito mais razão) é uma "máquina essencialmente capitalista" ${ }^{11}$.

A proteção dos consumidores, ao incidir sobre o excessivo desequilíbrio contratual, a concorrência desleal e a publicidade enganosa, busca, em regra, adequar os mecanismos de mercado à garantia do bom funcionamento do sistema.

Para alguns autores, dentre os quais aponta-se o professor RICARDO LUIS LORENZETTI, o Direito do Consumidor constitui um verdadeiro micro-sistema, expressão cunhada pelo professor da Universidade de Roma, NATALINO IRTI, na década de 70 e trazida ao Brasil por ORLANDO GOMES ${ }^{12}$.

Tal entendimento pode facilmente conduzir a uma perspectiva elitista e excludente do direito, notadamente ao se considerar a realidade dos países periféricos. Isto porque, atualmente, verifica-se uma "setorialização" das demandas, consubstanciada na "eleição" de certas classes ou de certas categorias de sujeitos a receberem maior proteção legislativa. Importa

8. SOUZA, Washington Peluso Albino de. Consideraçöes a respeito do Código de Proteção e Defesa do Consumidor. In: Revista de Direito Civil, n? 58, p. 104.

9. ALMEIDA, ob. cit., p. 25.

10. STROWEL, Alain. A la recherche de linterêt en économie. De l'utilitarisme à la science économique néo-classique. In: GÉRARD, Ph. et alli. Droit et intérét. Vol. 1: approche interósciplinaire, pp. 37-87.

11. GRAU, Eros. O discurso necliberale a teoria da regulação. In: CAMARGO, Ricardo Antônio Lucas (org.) Desenvolvimento económico e intervençăo do Estado na ordem constitucional - estudos jurídicos em homenagem ao Professor Washington Peluso Albino de Souza. Porto Alegre: Sergio Antonio Fabris, 1995, p. 63.

12. IRTI, Natalino. L'Età della Decodificazione. Milano: Giuffè, 1979. GOMES, Orlando. Caminho dos microssistemas. In: Novos temas de Direito Civil. Rio de Janeiro: Forense, 1983, pp. 40-50. 
observar que estes "iichos de proteção legislativa", convivem, em paradoxal harmonia, com a tendência acentuada de desregulamentação e flexibilização de determinadas relações jurídicas, como o contrato de trabalho, por exemplo.

Desde logo, porém, é prudente lembrar que o presente trabalho não se coloca ao lado daqueles que julgam inútil e alienante a proteção dos consumidores. Para esses "críticos incondicionais do sistema", conforme denomina ALMEIDA, os movimentos consumeristas constituiriam "manifestações do neo-reformismo capitalista, instrumentos das sociedades de capitalismo evoluído, que fazem as concessões necessárias para manter o mesmo sistema, mas de todo ineficazes para resolver as contradições das sociedades estruturadas na base do lucro máximo"13.

Em nosso modesto ver, não se pode negar que a necessidade de proteção do consumidor busca, fundamentalmente, fornecer maior equilíbrio às relaçōes de oferta $e$ procura, no mercado de bens de consumo, respondendu, com isso, às exigências dé constante reelaboração do capitalismo. É preciso, portanto, desmistificar as medidas de proteção que têm em vista a simples defesa do sistema e não dos consumidores.

Tal fato, todavia, não pode conduzir à mera e simples desconsideração de todos avanços que o direito do consumidor trouxe e tem trazido para a teoria contratual. Não se pode olvidar, ainda, das conquistas obtidas em decorrência das lutas sociais por melhores condiçốes de vida, fato que repercute necessariamente na ordem jurídica.

\section{Direito do consumidor $\mathbf{e}$ transformação social}

VITAL MOREIRA aponta que "quando a ordem econômica liberal é confrontada pela transformação da economia e das relaçōes sociais e é substituída por uma nova ordem que tem como elemento caracterizador a assumpção dos conflitos e das contradiçōes sociais -, então estes passam a caracterizar a própria ordem jurídica e constitucional"14.

Destarte, ainda que a ordem jurídica mantenha o fundamento do capitalismo e da propriedade privada como seu núcleo essencial, as transformações sócioeconômicas operadas nas sociedades de massa integraram, no ordenamento jurídico, elementos contraditórios à ordem capitalista.

Neste espaço de tensōes e contradições, segundo MOREIRA, é possível criar um campo de luta poítica, "levando as exigêñcias até ao limite da resistência do sistema"15.

A partir desta perspectiva de transformação, de particular importância, revela-se a investigação, a ser empunhada pela doutrina e pela jurisprudência, acerca de relações contratualizadas que, embora calcadas nos mesmos fundamentos (vulnerabilidade sócioeconômica de uma das partes), não possuem legislaçóes de caráter protetivo.

13. ALMEIDA, ob. cit., p. 225.

14. MOREIRA, Vital. A ordem jurídica do capitalismo. p. 267.

15. MOREIRA, Vital. Ob. cit., p. 271. 
Desde o advento do Código de Defesa do Consumidor, no entanto, reiteradas tem sido as decisões que negam a aplicabilidade dos dispositivos deste diploma legal para outros contratos, cuja delimitação não corresponda exatamente ao que se definiu como "relação de consumo".

O desafio que se apresenta para os estudiosos do Direito consiste em perquirir a possibilidade de aplicar-se dispositivos relativos à proteção do consumidor para contratos que tipicamente năo caracterizem uma relação de consumo, mas que sejam caracterizados pela hipossuficiência de uma das partes e pelo desequilíbrio contratual.

Os princípios, valores e direitos fundamentais presentes no texto constitucional, tais como, a dignidade da pessoa humana (art. 1으. III, CF), o compromisso com a construção de uma sociedade livre, justa e solidária (art. 3ㅇ, I, CF) e a redução da desigualdade social (art. 3으, III, CF), permitem a aplicação dos preceitos inovadores do Código de Defesa do Consumidor para relações contratuais em geral, não propriamente de consumo.

Nesse sentido, TEPEDINO defende que, "mediante a aplicação direta dos prinć́pios constitucionais nas relações de direito privado, devemos utilizar o Código do Consumidor, seja em contratos de adesão, mesmo quando não se constituam em relação de consumo, seja nas circunstâncias contratuais $\mathrm{em}$ que scjam identificados pela identidade de ratio, os pressupostos de legitimação da intervenção legislativa em matéria de relações de consumo"16.
Assim, a compreensão e a análise do tema exigem necessariamente o exame das relações contratuais à luz do texto da Constituição Federal de 1988, pois o pacto constitucional não só deve orientar o âmbito do direito privado, como também lhe impõe uma visão de solidariedade e de justiça social.

Consoante se intentou demonstrar, atualmente, as relaçōes contratuais (de consumo ou não), em regra, não interessam apenas aos sujeitos contratantes, mas constituem situaçōes jurídicas de forte repercussăo econômica e social.

Vários economistas estão engajados nissc e têm analisado os fenômenos do altruísmo, a preocupação com o interesse público, ou o engajamento em favor de valores sociais ou morais. Esta tentativa se impōe com mais força, na medida que o modelo econômico tradicional, dito neoclássico, está sendo levado para outras esferas sociais além da produção e do consumo de bens privados, especialmente para a esfera jurídica ${ }^{17}$.

A constatação da hipossuficieiencia (ou vulnerabilidade, como preferem alguns) de um dos pólos da relação contratual autoriza e exige a adoção de medidas protetivas.

A esta situação, alguns autores denominam de "renascimento da autonomia da vontade protegida". Segundo demonstra a professora CLÁUDIA LIMA MARQUES, busca-se agora "garantir uma autonomia real da vontade do contratante mais fraco, uma vontade protegida pelo direito, vontade li-

\footnotetext{
16. TEPEDINO, Gustavo. As relaçóes de consumo e a nova teoria contratual. In: Temas de Direito Civil. Rio de Janeiro: Renovar, 1999, p. 213.
}

17. STROWEL, Alain. Ob. cit. 
berta das pressões e dos desejos impostos pela publicidade e por outros métodos agressivos de venda. Esta nova autonomia foi denominada por NICOLE CHARBIN de vontade racional"18 e muda exatamente o sentido do dogma mais tradicional da teoria contratual: a autonomia da vontade. Segundo explica MARQUES, "conceitos tradicionais como os do negócio jurídico e da autonomia da vontade permanecerão, mas o espaço reservado para que os particulares auto-regulem suas relações será reduzido por normas imperativas, como as do próprio Código de Defesa do Consumidor.

Assim, impõe-se com maior vigor a limitação da categoria da autonomia privada através da inserção de outros elementos integradores da relação contratual, como a boa-fé e a justiça social.

Neste sentido, resgata-se o entendimento de COUTO E SILVA, para quem a autonomia da vontade "continua a ocupar lugar de relevo dentro da ordem jurídica privada, mas, a seu lado, a dogmática moderna admite a jurisdicização de certos interesses, em cujo núcleo não se manifesta o aspecto volitivo" ${ }^{19}$.

STIGLITZ, por sua vez, propõe a incorporação da solidariedade como cláusula aberta e oxigenante dos contratos, que justifica a intervenção do ordenamento jurídico para preservar-se um mínimo de "justiça contratual". Para este autor, "o contrato deve ser concebido com uma mínima dose de sensibilidade, ou, se se prefere, de humanidade, pois se aceitamos que não se trata de um fenômeno factível de ser reduzido a uma operação econômica, também haveremos de concordar que sua função, predominantemente, consiste em satisfazer e tutelar necessidades e interesses legítimos"20.

Enfim, o que se propõe é, a partir do reconhecimento de uma função social das obrigações $^{21}$, a busca da priorização do ser humano (e não mais do sujeito de direito ou do homo economicus) face à lógica do mercado.

Não se trata de privilegiar a igualdade, em detrimento da liberdade, opção que, de forma maniqueísta, se costuma impor. Apenas, quem sabe, resgatar a fraternidade - terceira bandeira sobre a qual se apoiaram (formal e retoricamente) as revoluções burguesas - mas que até hoje vem sendo sintomaticamente renegada ao esquecimento.

18. MARQUES, Cláudia Lima. In: prefácio à SILVA, Luís Renato Ferreira da. Revisão dos contratos: do código civil ao código do consumidor. Rio de Janeiro: Forense, 1998, p. XV.

19. COUTO E SILVA. V. A Obrigaçäo como Processo. Sảo Paulo: Bushatsky, 1976, p. 27.

20. STIGLITZ, Rubén S. Ob. cit.

21. O Projeto de Codigo Civil brasileiro prevê a funçăo social do contrato. Seu art. 421 dispōe que "A liberdade de contratar será exercida em razão e nos limites da funçăo social do contrato". 